\title{
Enhancement of Dissolution Rate of Ramipril Tablets by Solid Dispersion Technique
}

\author{
A. M. Abd El.Hay ${ }^{(1)}$, Sh. A. El.Adawy ${ }^{(2)}$ \\ ${ }^{\text {I}}$ Solid Dosage Forms Department, EIPICO, 10th of Ramadan City, Egypt, \\ ${ }^{2}$ Pharmaceutics and Industrial Pharmacy Department, Faculty of Pharmacy, Al-Azhar University, Cairo, Egypt.
}

\begin{abstract}
Ramipril is an ACE inhibitor mainly used for management of mild to severe hypertension and myocardial infarction. The poor solubility and wettability of Ramipril leads to poor dissolution and hence showing variations in bioavailability. The present study is aimed to improve the physicochemical properties of the drug using solid dispersion [SD] techniques. Solid dispersions [SDs] of ramipril were prepared with different polymers or carriers such as polyvinylpyrrolidone (PVP K25, PVP K30 and PVP K90), polyethylene glycol (PEG 4000 and PEG 6000) at three drug : carrier ratios (1:1), (1:2) and (1:3). Different methods such as melting and kneading methods were used. The formulations were characterized by X-Ray Diffractometry studies, Fourier transform infrared spectroscopy and in vitro dissolution rate studies. In contrast to the slow dissolution rate of pure Ramipril, the dispersion of the drug in the PEG4000 or 6000 considerably enhanced the dissolution rate. Furthermore; Ramipril $10 \mathrm{mg}$ immediate release tablets prepared in a ratio of 1:1 (drug: carrier) by the fusion method has been resulted in an acceptable dissolution results; $91 \%$ and $97 \%$ for ramiprilPEG4000 and ramipril-PEG6000 respectively.
\end{abstract}

Keywords: Ramipril, Solid Dispersion, Immediate Release Tablets.

\section{Introduction}

Ramipril is practically insoluble in water $(3.5 \mathrm{mg} / \mathrm{L})$. The poor solubility and wettability of Ramipril leads to poor dissolution and hence, variations in bioavailability ${ }^{[1]}$. Ramipril, ACE inhibitor mainly used for management of mild to severe hypertension and myocardial infarction, suffers from low bioavailability of $28 \%{ }^{[8]}$. Two main reasons for low bioavailability being its poor aqueous solubility and high first pass metabolism. Thus, increasing the aqueous solubility and dissolution of Ramipril is of therapeutic importance ${ }^{[1-4,}$ ${ }^{8]}$.The solid dispersion method is one of the selective approaches to achieve this ideal therapy particularly for drugs with poor aqueous solubility by incorporating them into a water-soluble polymer ${ }^{[4-6]}$ matrix (PEG 6000, 4000, PVP K25, K30 and K90)at three drug : carrier ratios (1:1), (1:2) and (1:3). After assessing the drug content in the solid dispersions, the products were characterized by Fourier transform infrared spectroscopy, powder X-ray diffraction and in-vitro dissolution rate studies. Tablets containing ramipril10mg were developed using the solid dispersions prepared by the fusion method.

\section{Materials}

\section{Materials And Methods}

Ramipril USP33 from Hetero Labs Limited (India), Polyethylene glycol 4000 and 6000 from Lyondel (France), polyvinyl povidone (K25, K30 and K90) from BASF (Germany), Microcrystalline cellulose from FMC (Ireland), Pregelatenized starch from Colorcon (England), Sodium stearylfumarate from JRS (Germany).

\section{Methods}

\section{Assay of Ramipril in 0.1N HCl using HPLC method ${ }^{[9]}$}

The HPLC analysis conditions were: $\mathrm{C}_{18}$ column, mobile phase: Acetonitrile: phosphate buffer $(30: 70 \% \mathrm{v} / \mathrm{v})$, column temperature: $25^{\circ} \mathrm{C}$, flow rate: $2.5 \mathrm{ml} /$ minute, wave length $215 \mathrm{~nm}$ and injection volume: $5 \mu \mathrm{l}$.

\section{Preparation of physical mixtures $[\mathrm{PM}]$ :}

The physical mixtures of ramipril and previously selected carriers in a ratio of 1:1, 1:2 and 1:3 (Drug: polymer) were prepared by homogeneous blending of previously sieved and weighed amounts of Ramipril with carriers in a glass mortar. The physical mixtures were subsequently passed through sieve $0.355 \mathrm{~mm}^{[7]}$ and stored in capped amber glass vials at room temperature until used ${ }^{[8]}$.

\section{Preparation of Solid Dispersions [SDs]}

3.1Applying of fusion (melting) method ${ }^{[1,5,6]}$ :

Ramipril, PEG 4000, and PEG 6000 respectively were melted on a water bath adjusted at $70^{\circ} \mathrm{C}$, mixed with the drug, triturated till cold. The prepared solid dispersions were passed through $0.355 \mathrm{~mm}$ and then treated as mentioned before. 
3.2Applying of kneading method ${ }^{[1,5]}$ :

A mixtures of Ramipril and carriers (PVP K25, PVP K30 and PVP K90), respectively, were wetted with water and kneaded thoroughly for 30 minutes in a glass mortar. The prepared solid dispersions were passed through $0.355 \mathrm{~mm}$ sieve and kept in capped amber glass vials away from light and humidity until use.

\section{FTIR Studies:}

FTIR spectra of pure Ramipril and Ramipril SDs were recorded with FTIR spectrometer using $\mathrm{KBr}$ disks. The scanning range used was 4000 to 500

$\mathrm{Cm}^{-1}$ at a scan period of 1 minute. Then the spectra were comparatively analyzed for drug-carrier interaction.

\section{X-ray Diffractometry [XRD] Studies:}

XRD was employed for tracing XRD patterns of Ramipril and SDs, using (Philips PAN analytical X' Pert PRO diffractometer with copper $\mathrm{K}(\alpha)$ radiation of wavelength $1.54 \mathrm{~A}^{\circ}$, Netherlands), operating at $45 \mathrm{KV}$ and $40 \mathrm{~mA}$. Diractograms were run at a scanning speed of $4 \%$ minute over a $2 \Theta$ rang of $0-80^{\circ} \mathrm{C}$.

\section{In-vitro dissolution studies ${ }^{[8-10]}$ :}

Drug release studies were performed in triplicate at $37 \pm 0.5$ OC employing USP apparatus II at $75 \mathrm{rpm}$. Dissolution study was carried out in dissolution media $(0.1 \mathrm{~N} \mathrm{HCl})$. Dissolution studies were performed on pure drug $(10 \mathrm{mg})$ and the SDs containing an equivalent amount of the drug. Aliquots of the periodically withdrawn samples $(1.5 \mathrm{ml})$ were analyzed using HPLC at $215 \mathrm{~nm}^{[9]}$.

\section{Formulation of Ramipril Tablet Dosage Forms:}

7.1Study of the possible interaction between the drug and the chosen additives:

Binary mixtures of Ramipril with avicel PH 102 and starch were incubated at $40^{\circ} \mathrm{C}$ for 90 days verses Ramipril. Drug assay was analyzed at $215 \mathrm{~nm}$.

\subsection{Preparation of Ramipril $10 \mathrm{mg}$ tablets using the prepared solid dispersions by the fusion method:}

Tablets were prepared according to the proportions given in table (1). The prepared solid dispersions prepared by the fusion method in a ratio of 1:1 (Ramipril: PEG 6000\& PEG $4000 \mathrm{w} / \mathrm{w}$ ) were then blended with $74.5 \mathrm{mg}$ microcrystalline cellulose $\mathrm{PH} 102,5.0 \mathrm{mg}$ pregelatenized starch glycolate and $0.5 \mathrm{mg}$ sodium stearylfumarate. The resultant blends were then compressed on punch $6.0 \mathrm{~mm}$ flat scored using Korsch XL 100 compression machine on target weight $100.0 \mathrm{mg}$ with hardness not less than $80.0 \mathrm{~N}$.

Table (1): composition of Ramipril 10mg Tablets

\begin{tabular}{|l|l|}
\hline Ingredients & \% \\
\hline Ramipril/ PEG4000 or PEG6000 SDs (1:1) & 20.0 \\
\hline Microcrystalline cellulose ( Avicel PH102) & 74.5 \\
\hline Pregelatenized starch glycolate & 5.0 \\
\hline sodium stearyl fumarate & 0.5 \\
\hline Total & 100.0 \\
\hline
\end{tabular}

\subsection{Evaluation of the compressed tablets ${ }^{[9,10]}$ :}

The prepared tablets were evaluated by determination of: uniformity of weight, disintegration time, resistance to crushing of tablets, friability, assay, loss on drying and dissolution in distilled water containing $0.1 \mathrm{~N} \mathrm{HCl}$ according to conditions mentioned in USP and BP 2013.

\section{Evaluation of the prepared Ramipril solid dispersions: \\ III. Results And Discussion}

\subsection{FTIR of the prepared Ramipril SDs:}

FTIR spectroscopy has been used to assess the interaction between drug and carriers molecules in the solid state. FTIR spectroscopy has been used to assess the interaction between drug and Carrier molecules in the solid state. Figures (1-6) illustrate the FT-IR spectra of the samples under study.The chemical interaction between the drug and Carrier often leads to identifiable changes in the infrared profile of dispersion. Drug spectrum shows prominent peaks at IR spectra of ramipril showing the peaks at $3400 \mathrm{~cm}^{-1}$ for $-\mathrm{NH}$ and $-\mathrm{OH}$, $2900 \mathrm{~cm}^{-1}$ for $-\mathrm{CH}$ aromatic streaching, $1730 \mathrm{~cm}^{-1}$ for $-\mathrm{C}=\mathrm{O}, 1320 \mathrm{~cm}^{-1}$ for- $\mathrm{CH}$ aliphatic bending. In general there was no chemical shift in the characteristic bands of Ramipril which means there no chemical interaction.

\subsection{Dissolution of Ramipril solid dispersions}

Figures (13-17) show the percent drug released from SDs in $0.1 \mathrm{~N} \mathrm{HCl}$ verses pure drug for $45 \mathrm{~min}$. The results obtained were the mean of three experiments. It is evident that the complexation technique has improved the dissolution rate of Ramipril to a great extent. As seen in figures (13-17); it was found that the complex 
prepared as Drug: PEG4000 and Drug: PEG6000 has shown improve in dissolution behavior as compare to pure drug and other complexes. This might be due to the inclusion complex formation, which indicates the improved solubility phenomenon.

\subsection{X-Ray Diffraction:}

Powder X-ray diffraction spectroscopy has been used to assess the degree of crystallinity of the given sample. When SDs of drug and (PEG4000, PEG6000, PVP K25, PVP K30 and PVP K90) are formed, the overall number of crystalline structure is reduced. The final product sample shows less number as well as less intensity of peaks. This shows that overall crystallinity of SDs is decreased and due to more amorphous nature, the solubility is increased. Figures (7-12) show the PXRD spectra of Ramipril and its SDs with the Desired Carriers. The diffractogram of SDs were found to be more diffuse compared to drug, there is no characteristic peak.

\section{Evaluation of the prepared Ramipril 10mg Tablets:}

2.1. Study of the possible interactions between the drug and the chosen Excipients:

Assay of Ramipril within binary mixtures of Ramipril with avicel PH 102 and starch verses pure Ramipril for three months were performed as shown in the following table.

Table (2)Assay of Ramipril for three months

\begin{tabular}{|l|l|l|l|l|}
\hline \multirow{3}{*}{$\begin{array}{l}\text { Vial at } \\
\mathbf{H}^{\circ} \mathbf{C}\end{array}$} & Binary Mixture & $\begin{array}{l}\text { Assay after one } \\
\text { month (\%) }\end{array}$ & $\begin{array}{l}\text { Assay after } \\
\text { Two months (\%) }\end{array}$ & $\begin{array}{l}\text { Assay after } \\
\text { Three months }(\%)\end{array}$ \\
\cline { 2 - 5 } & Pure Ramipril & 98.45 & 94.88 & 96.52 \\
\cline { 2 - 5 } & Ramipril+ Avicel (1:1) & 100.76 & 99.11 & 98.78 \\
\cline { 2 - 5 } & Ramipril+ Starch (1:1) & 106.28 & 105.43 & 104.20 \\
\hline
\end{tabular}

2.2. Uniformity of weight, disintegration time, friability, resistance to crushing of tablets, assay and loss on drying (LOD):

Tables $(2,3)$ show that the average weight of twenty tablets is very close to the target $100.0 \mathrm{mg}$. the disintegration time of the prepared tablets varies from 14.0 to 17.0 minutes. Friability results of the prepared tablets are less than $0.4 \%$. All hardness values are varying from 80.0 to $95.0 \mathrm{~N}$. Assay values are almost $100.0 \%$. Loss on drying values less than $1.5 \%$.

Table (3): Average weight, disintegration time and friability of Ramipril 10mg tablets from solid dispersions by fusion method

\begin{tabular}{|l|l|l|l|}
\hline $\begin{array}{l}\text { Ramipril tablets prepared } \\
\text { by: }\end{array}$ & Average weight (mg) & Disintegration time (min.) & Friability (\%) \\
\hline SDs With PEG4000 (1:1) & $99.3 \pm 2.5$ & $16.0 \pm 1.0$ & $0.13 \pm 0.02$ \\
\hline SDs with PEG6000 (1:1) & $99.6 \pm 2.1$ & $14.0 \pm 1.0$ & $0.12 \pm 0.01$ \\
\hline
\end{tabular}

Table (4): Assay, Hardness and loss on drying values of Ramipril 10mg tablets prepared from solid dispersions by fusion method

\begin{tabular}{|l|l|l|l|}
\hline Ramipril tablets prepared by: & Assay (\%) & Average hardness value (N) & Loss on drying (\%) \\
\hline SDs With PEG4000 (1:1) & $99.64 \pm 0.71$ & $84.8 \pm 4.30$ & $1.12 \pm 0.02$ \\
\hline SDs with PEG6000 (1:1) & $99.86 \pm 65$ & $88.3 \pm 5.1$ & $1.15 \pm 0.02$ \\
\hline
\end{tabular}

\subsection{Dissolution of Ramipril 10mg tablets in 0.1N HCl:}

Figures $(18,19)$ show that the dissolution values of the tablets prepared by SDs lie in required USP 33, BP 2013 for dissolution test 2 after 45 minutes. The dissolution of the prepared tablets are more than $75 \%$ after 45 minutes; $91 \%$ and $97 \%$ for ramipril-PEG4000 and ramipril-PEG6000 respectively.

\section{Figures}

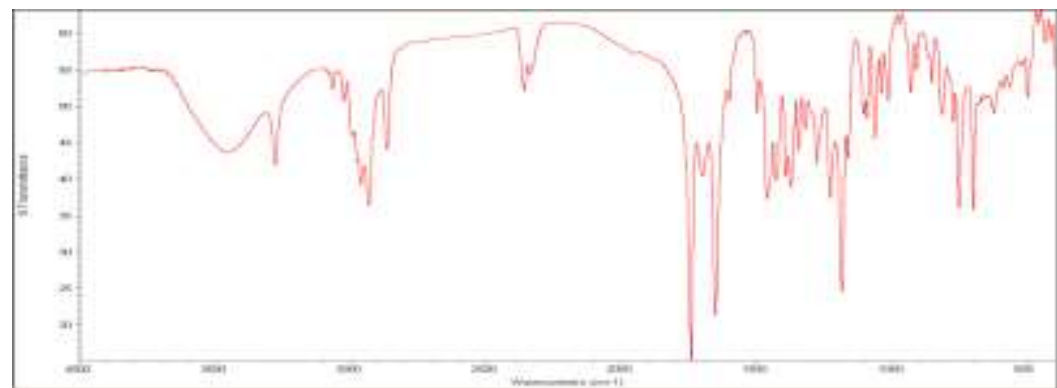

Fig. (1): FTIR spectra of Ramipril. 


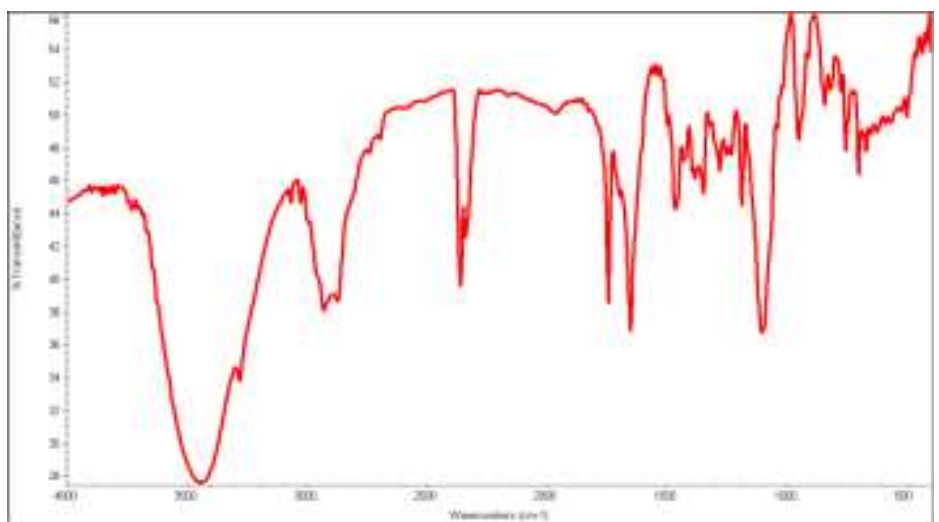

Fig. (2): FTIR spectra of RamiprilSDs with PEG4000 using fusion method.

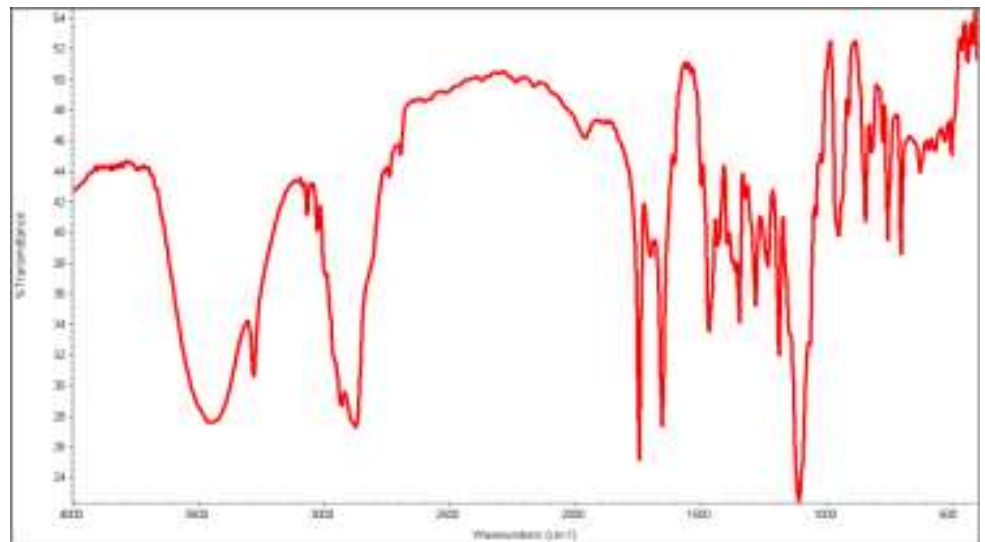

Fig. (3): FTIR spectra of RamiprilSDs with PEG6000 using fusion method

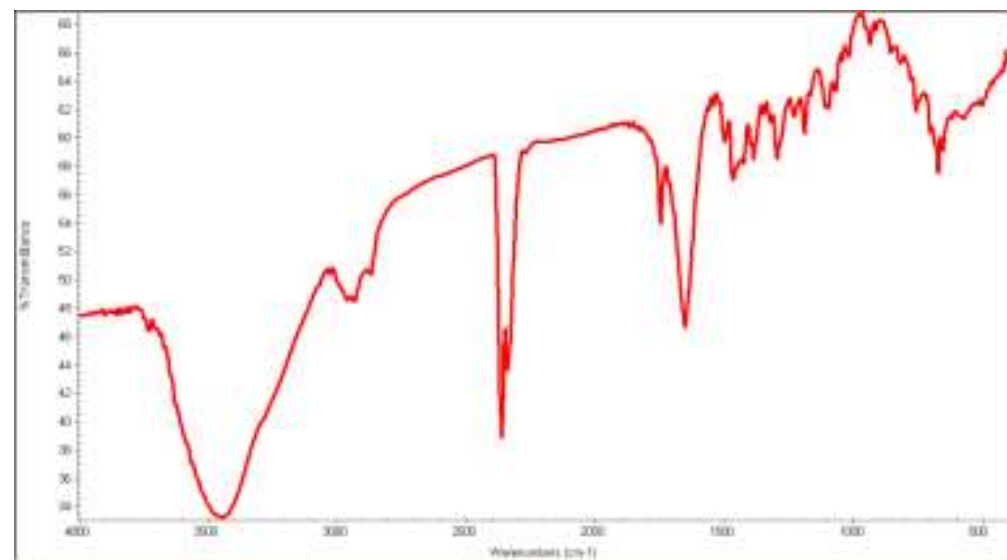

Fig. (4): FTIR of Ramipril SDs with PVP K25 using kneading method.

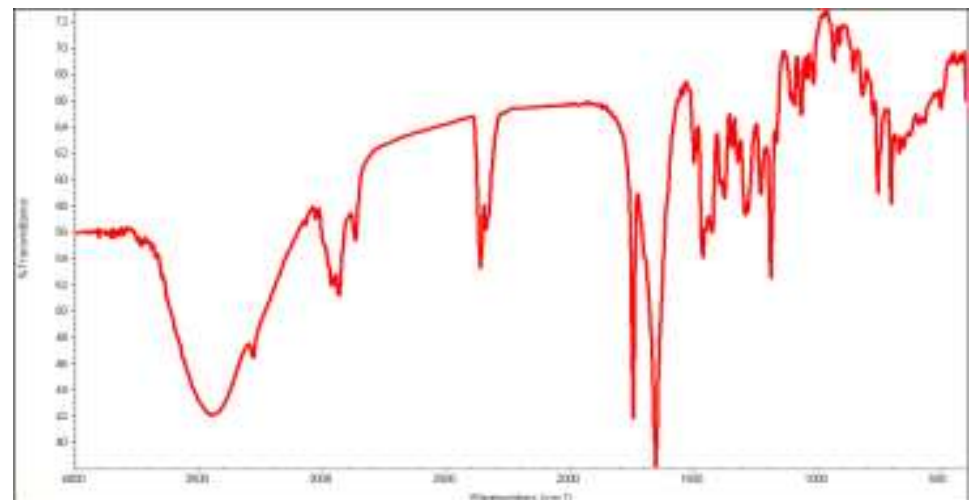

Fig. (5): FTIR of Ramipril SDs with PVP K30 using kneading method. 


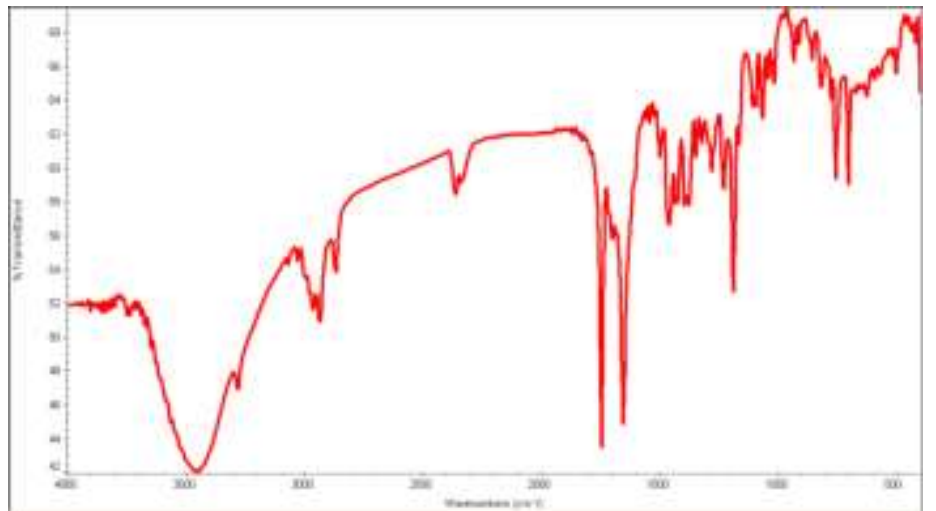

Fig. (6): FTIR of Ramipril SDs with PVP K90 using kneading method.

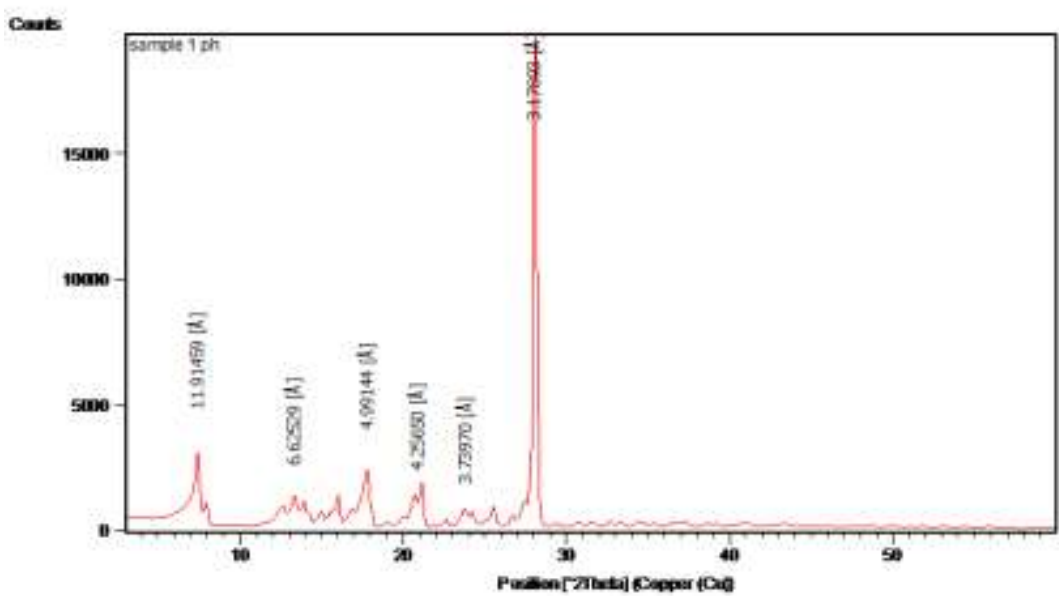

Fig. (7): X-ray Diffractogramof Ramipril.

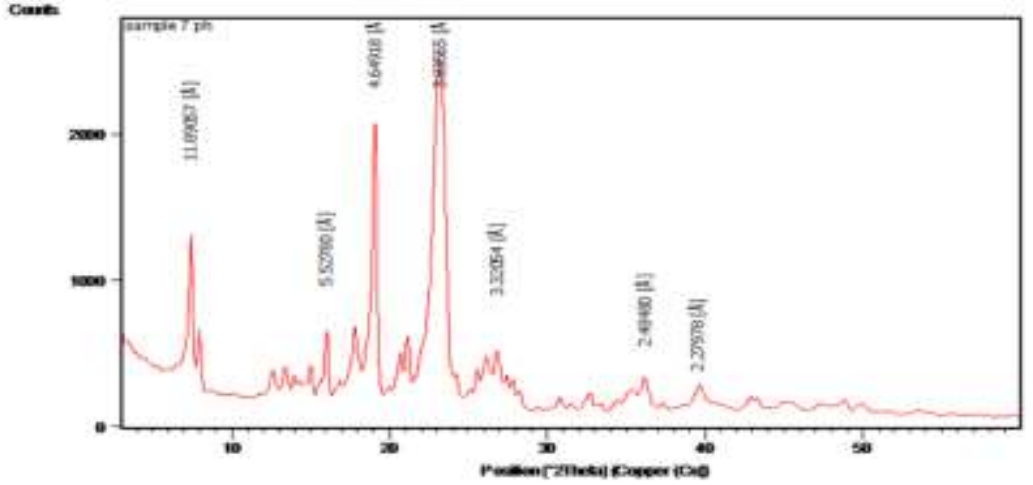

Fig. (8): X-ray Diffractogram of RamiprilSDs with PEG4000.

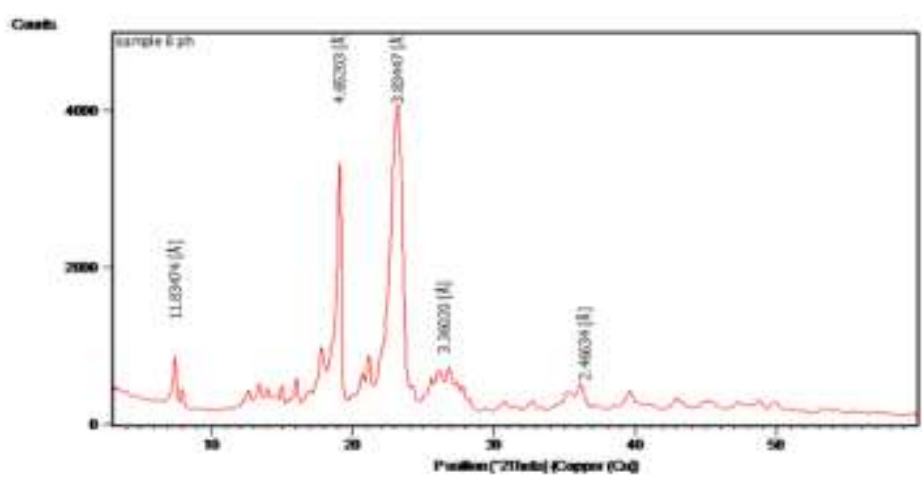

Fig. (9): X-ray Diffractogram of RamiprilSDs with PEG6000. 


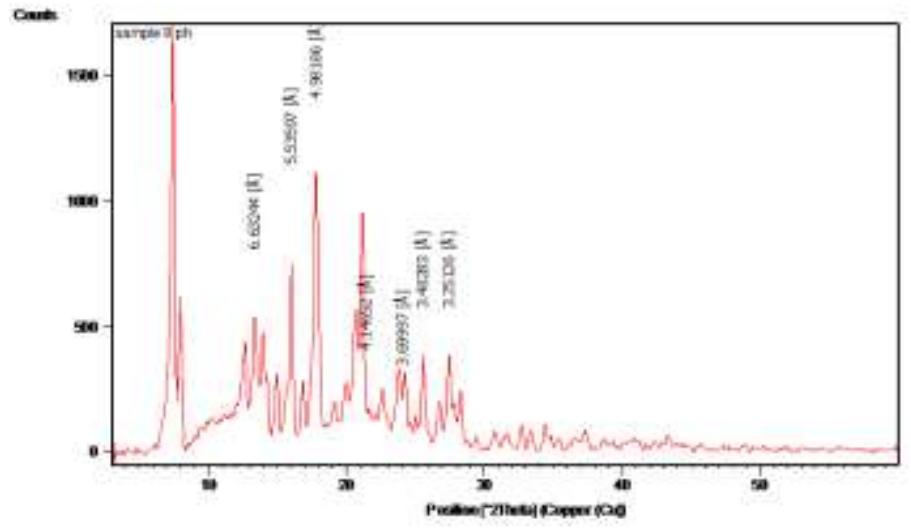

Fig. (10): X-ray Diffractogramof Ramipril SDs with PVP K25.

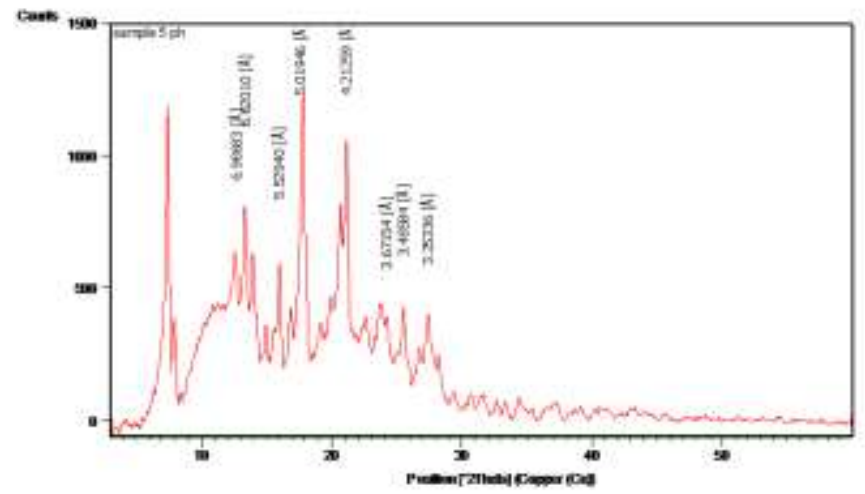

Fig. (11): X-ray Diffractogram of RamiprilSDs with PVP K30

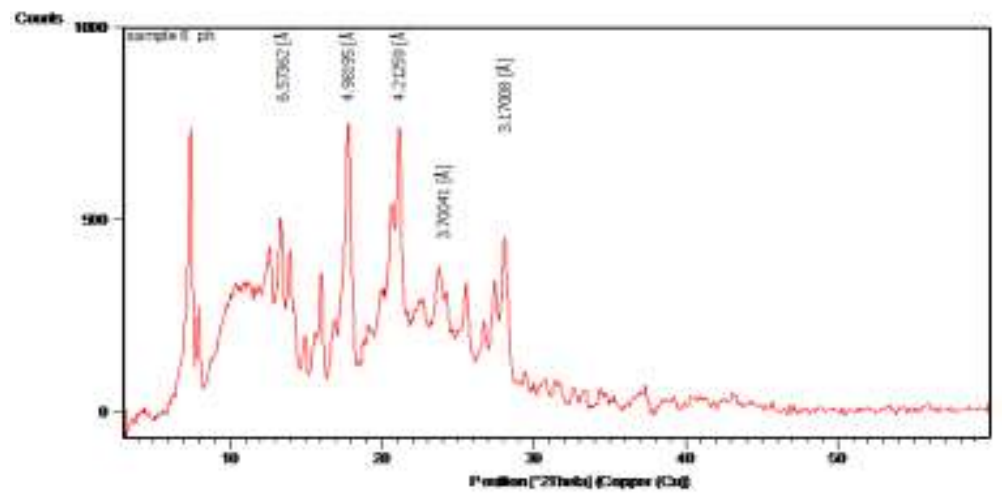

Fig. (12): X-ray Diffractogram of Ramipril SDs with PVP K90

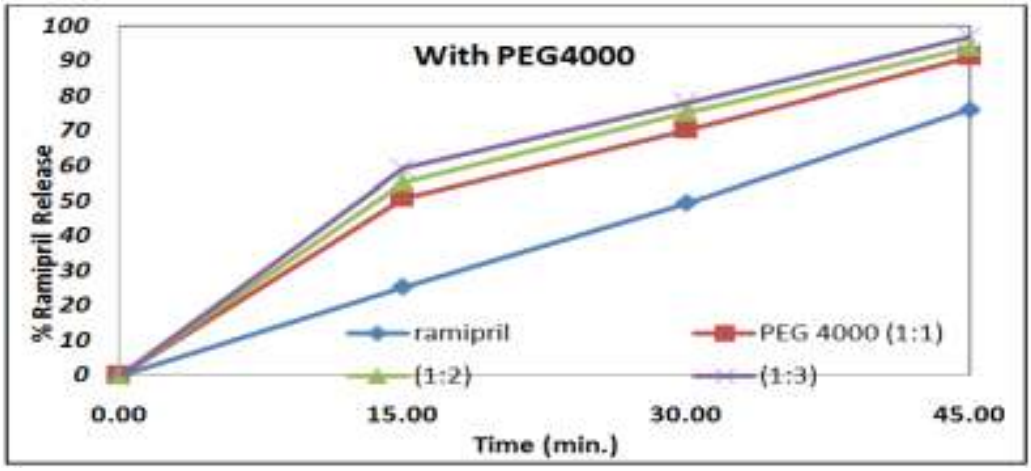

Fig. (13): Percent release of Ramipril versus its SDs with PEG 4000 in $0.1 \mathrm{~N} \mathrm{HCl}$. 


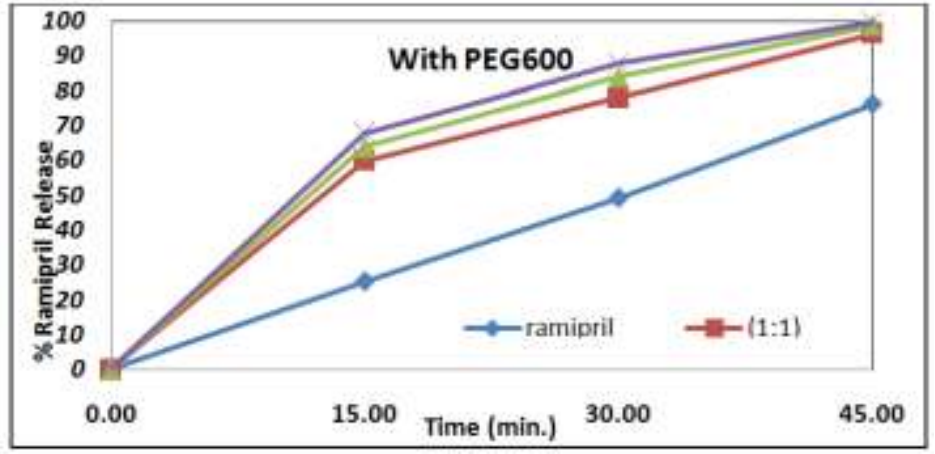

Fig. (14): Percent release of Ramipril versus its SDs with PEG 6000 in $0.1 \mathrm{~N} \mathrm{HCl}$.

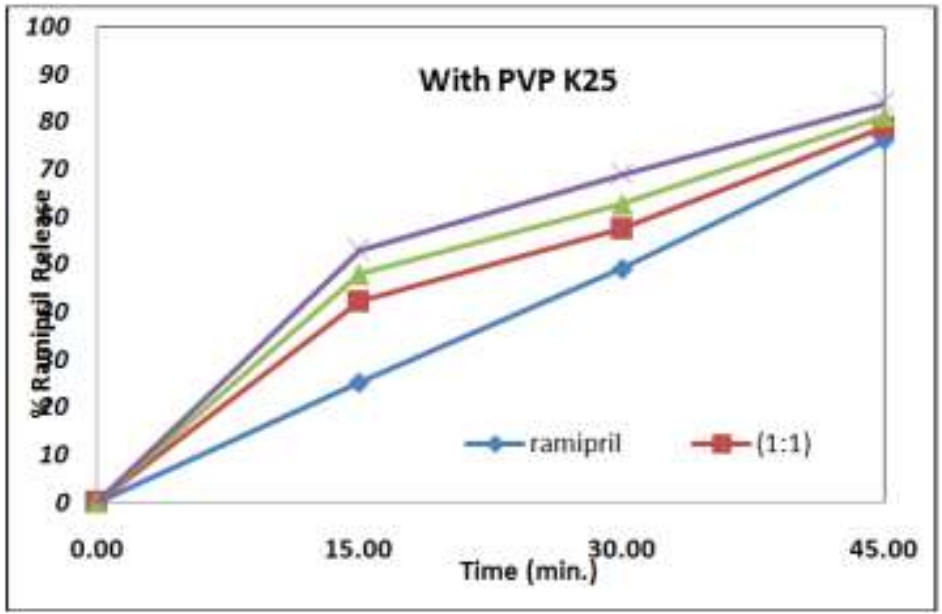

Fig. (15): Percent release of Ramiprilversus its SDs with PVP K25 in $0.1 \mathrm{~N} \mathrm{HCl}$.

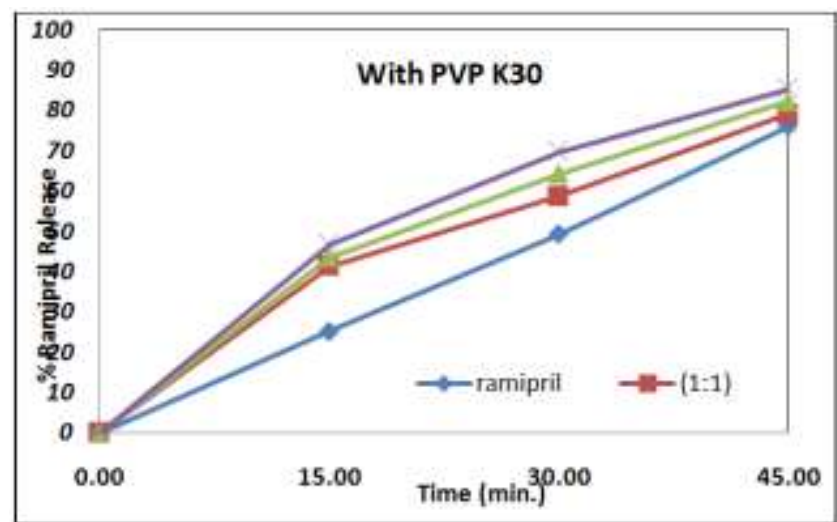

Fig. (16): Percent release of Ramipril versus its SDs with PVP K30 in $0.1 \mathrm{~N} \mathrm{HCl}$.

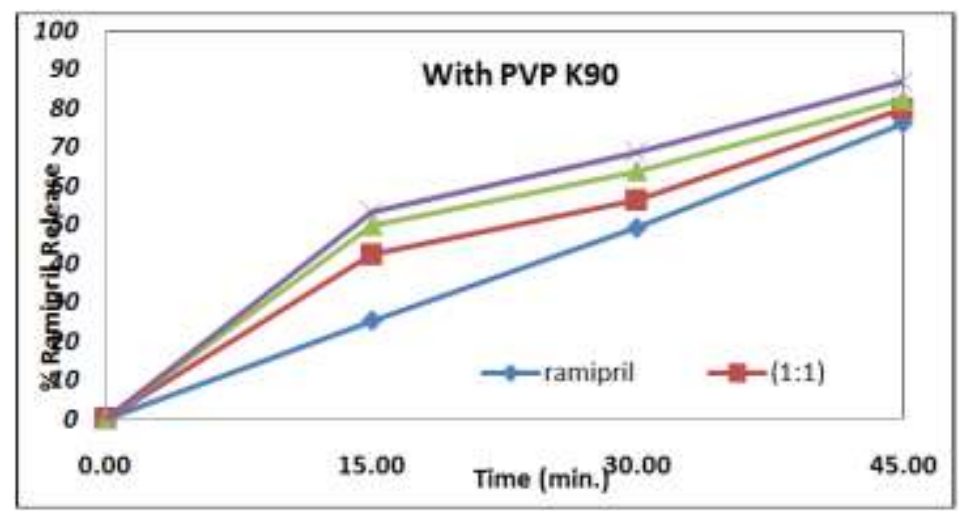

Fig. (17): Percent release of Ramipril versus its SDs with PVP K90 in $0.1 \mathrm{~N} \mathrm{HCl}$. 


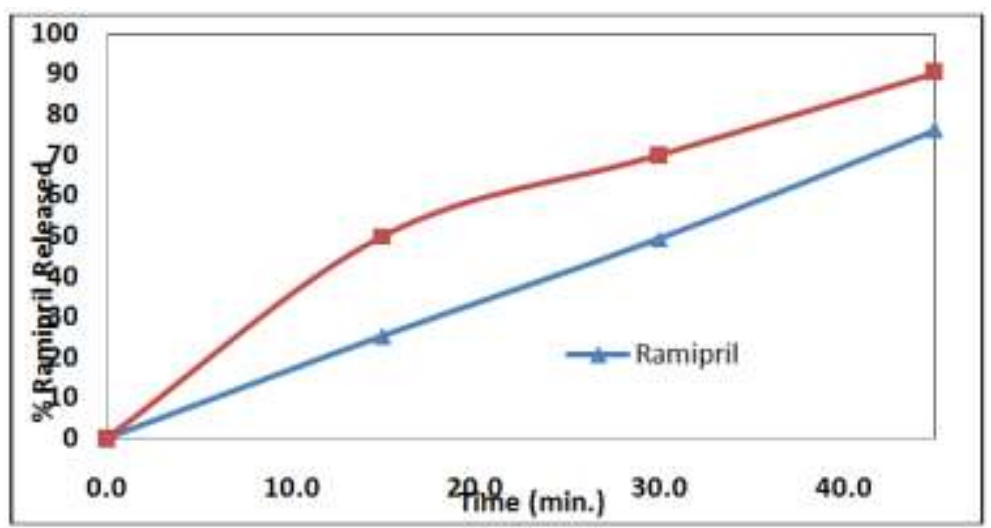

Fig. (18): Dissolution profile of Ramipril 10mg Tablets with PEG4000SDs.

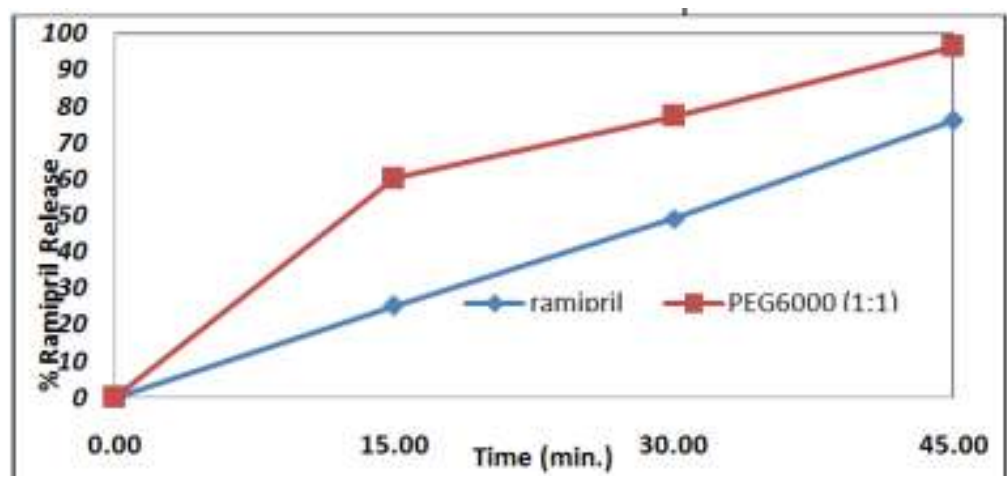

Fig. (19): Dissolution profile of Ramipril 10mg Tablets with PEG6000 SDs.

\section{Conclusions}

The use of PEG4000 and PEG6000 in equal ratios with Ramipril had enhanced the dissolution rate of the drug in comparison with pure untreated one. All prepared tablets fulfilled the pharmacopeal requirements concerning uniformity of weight, friability, hardness, loss on drying, drug content and dissolution results.

\section{References}

[1]. Swati Jagdale, Yashwant Dangat, Bhanudas Kuchekar, Improvement of dissolution rate of Ramipril by solid dispersion technique and development of buccal patch, international journal of pharmacy and pharmaceutical sciences, 4(5): 309-318, 2012.

[2]. Harish Chander, Sachin Kumar and Bineeta Bhatt, Formulation and evaluation of fast dissolving tablet of Ramipril, Pelagia Research Library, 2(6): 153-160, (2011).

[3]. Solid pharmaceutical formulations of Ramipril and Amlodipine besylate, and their preparation, EP2538924A2, 2013.

[4]. Chiou WL and Riegelman S. Pharmaceutical applications of solid dispersion systems, Journal of Pharmaceutical sciences. 60(9): 1281-1302, (1971).

[5]. Wael Ali, Alia A. Badawi, Mahmoud A. Mahdy and Hanan M. El-Nahas, Formulation and evaluation of carbamazepine solid dispersion with polyethylene glycol 6000 and their incorporation into tablets, International journal of basic and applied chemical sciences, 3(3): (11-20), (2013).

[6]. Verheyen S, Augustijns P, Kinget R and Van den Mooter G., Melting behavior of pure polyethylene glycol 6000 and polyethylene glycol 6000 solid dispersions containing diazepam or temazepam: a DSC study,ThermochimicaActa380,(153-164), (2001).

[7]. Kalia A, Khurana S and Bedi N.,Formulation and evaluation of mouth dissolving tablets of oxcarbazepine, International Journal of Pharmacy and Pharmaceutical Sciences 1(1):(12-23), (2009).

[8]. Miyan Syed Shariff, Ahamed Vazir Ashfaq, Kaleel Mohammed, Mohammed Yakhoob H., Formulation and evaluation of orodispersible tablets of an antihypertensive drug using superdisintegrants, Research journal of pharmaceutical dosage forms and technology, 3(6): (269-275), (2011).

[9]. Martindale (2009), the complete drug reference, 36th Edition. British Pharmacopeia, 2013.

[10]. British Pharmacopeia, 2013. 